\title{
PERSPEKTIF PENDIDIKAN MENENGAH DALAM SISTEM PENDIDIKAN NASIONAL INDONESIA
}

\author{
Oleh: Sudiyono
}

\begin{abstract}
Dari tujuan pendidikan nasional terlihat beberapa komponen penting yang melandasi pembangunan pendidikan nasional di Indonesia yang mengarah pada peningkatan kualitas manusia Indonesia seutuhnya dengan kreteria universal sebagai berikut:1) manusia yang bertakwa kepada Tuhan Yang Maha Esa, 2) manusia yang mempunyai pengetahuan dan keterampilan, kesehatan jasmani dan rohani, kepribadian yang mantap dan mandiri, 3) aspek kewarganegaraan yang tinggi.
\end{abstract}

\section{Kata Kunci : Pendidikan Menengah, Sistem, Peningkatan Kualitas}

\section{A. Pendahuluan}

Di Indonesia pendidikan menengah menjadi bagian penting dari proses pendidikan nasional yang berlangsung di Sekolah Menengah Umum dan Sekolah Menengah Kejuruan. Selain jenis ini, dalam UUSPN No.29 Tahun 1990, juga disebutkan ada Sekolah Menengah Keagamaan, Sekolah Menengah Kedinasan dan Sekolah Menengah Luar Biasa. SMU, yang semula bernama SMA dengan sistem penjurusan, mengalami perubahan pada tahun 1990 dengan berlakunya UUSPN No.29. Tahun 1990 Pendidikan menengah sebagai kelajutan pendidikan dasar mempunyai arti penting dalam mendidik anak yang sedang memasuki usia remaja. Ini artinya bahwa pendidikan akan memberikan sumbangan yang berarti bagi persiapan anak remaja untuk memasuki dunia sosial. Usia remaja merupakan usia yang penuh dinamika baik secara sosial, psikilogis dan biologis.

Pendidikan menengah sebagai salah satu sistem pendidikan nasional tidak lepas dari tujuan pendidikan nasional yang ideal dan praksis. Pendidikan akan memberikan rasional pemikiran atas berbagai sistem pendidikan yang ada. Untuk memahami tujuan pendidikan menengah lebih dahulu dipahami begaimana hakekat tujuan pendidikan nasional. Hal ini disebutkan secara jelas dalam UUSPN No.2 Tahun 1989, sebagai berikut:

"Pendidikan nasional bertujuan untuk mencerdaskan kehdiupan bangsa dan mengembangkan manusia Indonesia seutuhnya, yaitu manusia yang beriman dan

\footnotetext{
* Penulis adalah Ketua Program Akta VI Fahultas Tarbiyah UIIS Malang dan kini menjadi mahasiswa Program Manajemen Pendidikan Pascasarjana UNM Malang
} 
bertaqwa terhadap Tuhan Yang Maha Esa dan berbudi pekerti luhur, memiliki pengetahuan dan keterampilan, kesehatan jasmani dan rohani, kepribadian yang mantap dan mandiri serta rasa tanggung jawab kemasyarakatan dan kebangsaan “(pasal. 4).

Dari tujuan pendidikan nasional tersebut paling tidak dapat dilihat bahwa ada beberapa komponen penting yang melandasi pembangunan pendidikan nasional di Indonesia yang mengarah pada peningkatan kualitas manusia Indonesia seutuhnya dengan kreteria universal sebagai berikut:1 ) manusia yang bertakwa kepada Tuhan Yang Maha Esa, 2) manusia yang mempunyai pengetahuan dan keterampilan, kesehatan jasmani dan rohani, kepribadian yang mantap dan mandiri, 3) aspek kewarganegaraan yang tinggi.

Ketiga aspek diatas merupakan domain utama yang harus dicapai oleh pendidikan nasional, yang memberikan sumbangan penting untuk meningkatkan kualitas sumber daya manusia Indonesia. Pendidikan nasional harus mampu untuk membangun dan meningkatkan kualitas manusia Indonesia untuk kebutuhan pembangunan kebudayaan modern (Tilaar: 1999). Pendidikan adalah sebagai proses untuk membangun kebudayaan yang lebih dihargai lingkungan sekitarnya. Tidak saja terhenti sampai di situ, tapi bagaimana agar manusia Indonesia berperan proaktif dalam menghadapi kemajuan ilmu pengetahuan dan teknologi yang berlangsung amat cepat. Disinilah tugas pendidikan untuk memberikan kemampuan (skill) yang relevan dengan kebutuhan ilmu pengetahuan dan teknologi, yang mempengaruhi berbagai sektor kehidupan seperti budaya, ekonomi, politik, hukum dan seterusnya.

Sebagaimana tujuan pendidikan untuk meningkatkan dan mengembangkan kedewasaan peserta didik, maka pendidikan menengah memberi perhatian pada hal ini dalam rangka siswa mampu menghadapi kehidupan sosial di tengah masyarakat. Dengan pendidikan yang cukup dan baik, maka anak didik atau lulusan (out put) mampu menghadapi tingkat perubahan sosial yang tinggi di tengah masyarakat. Lebih-lebih bahwa pada usia pendidikan menengah, kondisi siswa sedang berada dalam perkembangan sosial dan kejiwaan dengan berbagai tantangan yang ada di masyarakat mulai dari proses penyesuaian diri dengan dunia baru sampai keharusan untuk menghadapi dunia kerja sebagai tuntutan sosial, setelah lulus sekolah bagi yang tidak melanjutkannya ke perguruan tinggi.

Lebih lanjut bahwa secara khusus tujuan pendidikan menengah dijelaskan pada UUSPN No. 2 Tahun 1989 sebagai berikut;

"Pendidikan menengah diselenggarakan untuk melanjutkan dan meluaskan pendidikan dasar serta menyiapkan peserta didik menjadi anggota masyarakat yang memiliki kemampuan mengadakan timbal balik dengan lingkungan sosial, budaya dan alam sekitar serta dapat mengembangkan kemampuan lebih lanjut dalam dunia kerja atau pendidikan tinggi"(Bab Ketiga, pasal.15). Sedangkan dalam PP No. 29 Tahun 1990 disebutkan tujuan pendidikan menengah yaitu: a)Meningkatkan 
pengetahuan siswa untuk melanjutkan pendidikan pada jenjang yang lebih tinggi dan untuk mengembangkan diri sejalan dengan perkembangan ilmu pengetahuan, teknologi dan kesenian, b)Meningkatkan kemampuan siswa sebagai anggota masyarakat dalam mengadakan hubungan timbal-balik dengan lingkungan sosial, budaya dan alam sekitarnya (pasal 2).

Dalam jabaran tersebut, dapat dipahami aspek-aspek utama dari tujuan pendidikan menengah, yaitu pertama, peserta didik diharapkan menjadi anggota masyarakat (citizen) yang mampu berinteraksi dengan lingkungan sosial, budaya dan alam sekitar, kedua, peserta didik disiapkan untuk memasuki dunia kerja, dan ketiga, peserta didik disiapkan untuk melanjutkan studi ke perguruan tinggi.

Ketiga aspek ini, juga mempengaruhi tingkat prestasi siswa di Jepang pada sekolah menengah (Rohlen, 1985). Hasil penelitiannya pada beberapa sekolah di Otani High School, Nada High School, Sakura High School, Okada High School dan Yama High School menemukan bahwa prestasi akademik, moral kerja, prilaku berkaitan denagan keinginan siswa yang tinggi untuk masuk dunia kerja dan perguruan tinggi.

Aspek Pertama, membangun kesiapan anak remaja menjadi warga negara. Aspek utama dalam jenjang pendidikan ini adalah bagaimana memberikan kesempatan bagi peserta didik untuk mengembangkan kemampuan yang relatif belum matang secara kognitif, afektif dan psikomotorik. Para peserta didik di pendidikan menengah merupakan anak remaja yang membutuhkan pendidikan agar siap menjadi anggota masyarakat. Disinilah perlunya menekankan pendidikan mengemban fungsi sosial (education as a social function), seperti diungkapkan John Dewey (1944). Dalam fungsi ini, pendidikan menengah mengarah pada bagaimana siswa memahami dan menyadari dirinya sebagai bagian dari kehidupan sosial yang berlaku di tengah masyarakat. Kompleksitas kehidupan sosial yang terjadi seperti ekonomi, politik, budaya, agama dan sebagainya agar mampu dipahami dalam kapasitasnya sebagai warga negara. Itulah sebabnya sejak dini siswa dikenalkan dengan kondisi sosial masyarakat agar dapat beradaptasi dengan lingkungan sekitar. Dan khususnya agar siswa dipersiapkan menjadi warga negara untuk memahami serta menyadari berbagai hak dan kewajibannya dalam kehidupan berbangsa, bernegara dan bermasyarakat.

Tujuan pendidikan menengah untuk membangun kesiapan anak remaja untuk menjadi anggota masyarakat dan warga negara akan menempatkan pembangunan pendidikan sebagai bagian penting dari kehidupan berbangsa dan bernegara. Ini artinya, bahwa seorang anak, yang sedang menjelang remaja, harus dipersiapkan dengan nilai, pandangan hidup dan tata moral yang selaras dengan kebudayaan yang dimiliki bangsa Indonesia(Tilaar,1999). Meningkatkan rasa nasionalisme melalui pendidikan untuk membangun dan menjaga ketahanan nasional (Ruwiyanto, 1997; Buchari, 2001). Hal ini penting agar para remaja tidak terbawa pada arus budaya 
liberalisme dan bertentangan dengan nilai-nilai dasar budaya bangsa Indonesia. Yang sering terjadi dalam usia pendidikan menengah adalah kecenderungan anak untuk men-judgment budaya yang dianggap menghalangi kesenangan dan keinginannya, sehingga terkadang ia menentang budaya yang sedang berlaku di tengah masyarakat.

Aspek Kedua, pendidikan menengah menekankan aspek ekonomis dengan bertujuan mempersiapkan anak didik memasuki dunia kerja. Hal ini merupakan tanggung jawab pendidikan nasional untuk memberikan kemampuan praktis kepada peserta didik untuk menguasai berbagai kompetensi yang dibutuhkan dunia industri, yang akhimya dengan harapan bahwa lulusan dapat diterima di dunia kerja(Boediono, 1997; Suryadi, 1994). Penekanan pendidikan menengah untuk menyiapkan peserta didik ke dunia kerja merupakan upaya untuk membangun kesempatan sedini mungkin kepada siswa untuk terjun ke kehidupan masyarakat yang lebih praktis dan aplikatif. Inilah kemudian yang menjadi strategi pendidikan nasional yaitu membangun dan meningkatkan relevansi pendidikan dengan dunia kerja. Disinilah sasaran ekonomis pendidikan menengah untuk meningkatkan kualitas sumber daya manusia yang mempunyai kompetensi yang dibutuhkan dunia industri atau dunia kerja.

Hal ini sangat erat kaitannya dengan fungsi pendidikan dalam mengahadapi perubahan dan membangun perubahan sosial di tengah masyarakat (Husen,1979). Karena pendidikan sesungguhnya mempunyai hubungan kausalitas dengan perubahan itu sendiri. Sekalipun Illich(1974) meragukan 'kejujuran' sekolah dalam membangun perubahan tersebut, dengan mengatakan bahwa sekolah cenderung bersifat kafitalistik dan membatasi, mengelompokkan anak dalam sebuah "institusi" yang namanya sekolah dengan mengenyampingkan aspek egaliterianism dalam semua aspek anak didik.

Pendidikan menengah tentunya akan memberikan sumbangan besar terhadap siswa agar siap menghadapi kemajuan ilmu pengetahuan dan teknologi. Dalam posisnya sebagai anggota masyarakat dan warga negara, setidaknya siswa memiliki beberapa aspek penting dari segi kompetensi akademis dan kompetensi sosial untuk siap proaktif terhadap dunia kerja yang ada, baik sektor industri manufaktur dan jasa.

Pendidikan menengah diharapkan dapat memberikan kontribusi dalam rangka mengarahkan dan membina perkembangan, bakat dan kemampuan yang dimiliki masing-masing siswa. Pendidikan menengah akan memberikan ilmu pengetahuan kepada siswa tentang bagaiamana prinsip-prinsip kehidupan bermasyarakat. Demikian juga ilmu pengetahuan yang diberikan kepada siswa hendaknya relevan dengan kebutuahan untuk mengahadapi segala problematika kehidupan sosial.

Asepk ketiga, bahwa tujuan pendidikan menengah adalah untuk menyiapkan lulusannya melanjutkan studi ke perguruan tinggi. Pada sekolah menengah siswa mendapatkan kemampuan dasar yang akan dikembangkan lebih lanjut di perguruan 
tinggi. Pada masa di sekolah menengah siswa mampu diketahui bakat dan minatnya dalam bidang ilmu pengetahuan. Di sini jelas bahwa fungsi pendidikan pada masa ini untuk mengantarkan siswa memasuki pendidikan tinggi. Dengan harapan bahwa di pendidikan tinggi siswa mampu mengembangkan keahlian akademis dan praktis sehingga ia dapat menjadi tenaga ahli tingkat menengah.

Berkaitan dengan tujuan di atas, maka pendidikan menengah memberikan kesempatan kepada siswa untuk menguasai dasar-dasar keilmuan yang diharapkan dapat dilanjutkan manakala berada di perguruan tinggi. Kemampuan-kemampuan dasar, seperti menghitung, dan berbahasa menjadi kemampuan dasar yang harus dimiliki siswa. Dan yang lebih penting adalah kemampuan pendidikan menengah untuk merespon perubahan yang terjadi dalam perkembangan ilmu pengetahuan dan teknologi, terutama di perguruan tinggi. Dari sinilah diperlukan sebuah kerja sama antara pendidikan menengh dan pihak perguruan tinggi untuk membangun kesinambungan dalam mengembangkan ilmu pengetahuan dan teknologi.

\section{B. Orientasi Pendidikan Menengah: Perspektif Pembangunan SDM}

Gagasan sekolah menengah di Amerika (Gutek, 1991) muncul pada pertengahan abad ke 19 yang disebut The High School, tepatnya pada tahun 1920. Sekolah ini terdiri dari berberapa karaketersitik; 1) program persiapan ke perguruan tinggi. 2) program komersial dan bussines,3) program industri, vocational, ekonomi keumahtanggaan, dan pertanian, dan 4) perpaduan antara industri, dan vocational. Pendidikan menengah di Amerika bertujuan untuk memberikan kemampuan kepada siswa untuk memasuki dunia kerja dan untuk melanjutkan studi ke perguruan tinggi. Dan pada akhimya kebutuhan akan pada lulusan sekolah untuk memasuki dunia kerja, baik di sektor industri manufaktur atau jasa.

Itulah sebabnya bahwa pendidikan di Amerika pada abd ke 21 diarahkan pada tiga sasaran utama yaitu tujuan politis, sosial dan ekonomis (Goaled, 1989). Lebih lanjut Goaled menjelaskan :

“.... Political goal refers to attempt use educational system to mold future citzen , mantain political stability, and shape political system. Social goal include attempt to reform society, and give direction for social development. Economic goal; involve to use public school system to sort and select talent for labor markert, develop human cafital, and plan economic development.."

Sama halnya di Jepang bahwa pendidikan menengah lebih terarah pada penyiapan lulusan untuk memasuki dunia kerja dan perguruan tinggi(Rohlen,1983). Hanya saja, pendidikan menengah di Jepang lebih menekankan fungsi pendidikan sebagai proses sosialisasi. Sehingga peran dominan ajaran Kongfucu yang mengajarkan tata krama dalam keluarga (Rohlen, 1983), yang bersifat tradisional, memberikan warna tersendiri bagi pendidikan di tingkat lanjut. Nilai-nilai tradisonal dipadukan dengan nilai modern di lingkungan sekolah. Sehinggan kalangan generasi 
muda Jepang sangat menghargai nilai tradisional. Kebutuhan yang tinggi negara ini akan tenaga kerja profesional pada industri manufaktur, maka arah kebijakan pendidikan untuk menghasilkan tenaga kerja profesional dalam bidang teknologi, elektronik, pembelajaran, kedokteran dan lain-lain (Ichkawa, dalam Hough, 1984). Sehingga kebijakan sistem pendidikan dangan dunia kerja selalu menjadi perhatian penting negara ini. Sehingga tidak heran bahwa pendidikan di Jepang mempunyai ekonomi dan non-ekonomis.

Penelitian Husen (1979) tentang pendidikan menengah dan hubungan dengan masyarakat, di beberapa negara Barat, mengalami beberapa krisis, antara lain; terjadinya krisis ideologi pendidikan, krisis kelembagaan, krisis pembelajaran, krisis relavansi dan seterusnya. Krisis ini berlangsung manakala berhadapan dengan perkembangan sosial masyarakat, terutama ilmu pengetahuan dan teknologi yang cukup cepat, tapi lamban disikapi. Lebih lanjut ia menjelaskan tentang trend perkembangan pendidikan ini, meliputi beberapa hal penting dalam rangka mempersiapkan lulusan memasuki kehidupan di tengah masyarakat, yaitu; peranan tenaga kerja, permasalahan remaja, masa transisi dari remaja ke dewasa, budaya dan nilai remaja, pendidikan dan dunia kerja. Ini artinya bahwa pendidikan menengah sangat terkait erat dengan kompleksitas sosial siswa, sebagai sasaran pendidikan tersebut, termasuk dunia kerja dimana lulusan dapat tertampung nantinya. Itulah sebabnya Husen (1979) menyarankan agar pendidikan di SMU lebih diarahkan pada kesiapan lulusan untuk memasuki dunia kerja.

Tidak bisa dipungkiri bahwa pembangunan pendidikan dalam semua jenjang, khsusnya pendidikan menengah harus meperhatikan perkembangan global yang terus berlangsung. Lebih-lebih pada saat ini, globalisaisi dalam bidang ekonomi,budaya dan bahkan politik akan memberikan pengaruh yang luar biasa pada pendidikan di di semua negara. Tilaar (1997) menyebutkan ada empat kekuatan global yang mengarahkan, yang disebutnya Catur Santika Saruka, yaitu: 1) Kerja sama regional dan internasional, 2) Demokrasi dan Hak Asasi manusia, 3)Ilmu pengetahuan, teknologi dan moral, 4) Identitas bangsa. Kecenderungan ini merupakan tugas pendidikan menengah untuk lebih proaktif dalam menghadapi perubahan dan gaya kehidupan sosial-masyarakat, khususnya kalangan remaja, yang semakin hari semakin membutuhkan sistem pendidikan yang mampu menjawab tantang tersebut.

Namun pada akhirnya pendidikan adalah berupaya untuk memberikan sumbangan sumber daya manusia yang berkualitas bagi pembangunan di semua bidang, sehingga mempunyai tanggung jawab untuk meningkatkan kualitas kompetensi lulusan semua jenjang pendidikan. Tentunya dalam menghadapi dunia global ini, maka arah bangunan kompetensi secara umum yang harus dimiliki lulusan sekolah, meliputi: 1)ikut menggalang perdamaian dan ketertiban dunia, 2)mempersipakan pribadi sebagai warga negara dan masyarakat, 3) pendidikan 
yang merata dan menyuluruh, 4) menanamkan dasar-dasar pembangunan yang berkelanjutan dan pelestraian leingkungan, 5)mempersiapkna tenaga kerja untuk pembangunan ekonomi sehingga pendidikan perlu dikaitkan dengan kebutuhan dunia kerja, 6) berorientasi pada penguasaan dan pengembangan ilmu pengetahuan dan tekenologi(UNISCO, 1995). Dalam lingkup yang lebih spesifik, bahwa kompetensi yang dimiliki lulusan pendidikan menengah harus merupakan perpaduan antara potensi lokal yang mempunyai akses secara nasional dan internasional. Kompetensi lulusan harus mengarah pada pengausaan iptek yang berwawasan lingkungan dan perkembangan masyarakat. Salah satu contoh mungkin bagaimana seorang siswa mampu membangun potensi lokal yang ada di sekitarnya agar mempunyai nilai tambah (vuleu added) secara ekonomi dan sosial. Hal ini dapat dilihat di hasil kerajian di Bali dan Lombok yang mempunyai daya ekonomis yang tinggi di tingkat internasional.

\section{Pendidikan Menengah Realitas dan Masa Depan}

Dalam sistem pendidikan nasional, pendidikan menengah sangat mempunyai arti penting bagi peningkatan kualitas manusia Indonesia. Tidak saja untuk membangun kesiapan.generasi muda untuk menghadapi kelangsungan hidup di tengah masyarakat, tapi lebih dari itu adalah ia akan menjadi bagian penting dari bangunan tatanan berbangsa dan bernegara, baik pada sekala regional, nasional dan internasional. Lebih-lebih masa remaja di sekolah menengah merupakan masa transisi secara psikologis, biologis dan sosial menuju pasca remaja yang memberikan arah masa depan. Menjalani masa transisi ini, seorang remaja, tidak hanya cukup dengan pendidikan dari sekolah saja, tapi juga peran serta keluarga dan lingkungan sekitarnya untuk membimbing perkembangan anak remaja ke arah yang positif bagi masa depannya.

Data statistik tahun 2000 (Kompas, 20/4/0 l) menunjukkan bahwa angka putus sekolah pada jenjang SLTA masih cukup tinggi, yaitu sekitar 159.900 siswa $(3,41$ persen), belum lagi pada tingkat SD 778.457 anak (3,03 persen) dan SLTP 389.346. Hal ni akan diperparah lagi dengan tingginya angka pengangguran dari semua jenjang pendidikan yang terus meningkat karena belum kuatnya relevansi pendidikan dengan perkembangan ekonomi (Aris, 1997). Ini artinya bahwa tugas pendidikan untuk meningkatkan sumber daya manusia masih sangat prlu dimaksimalkan, baik kualitas, relevansi dan proses pendidikan itu sendiri. Lebih-lebih pendidikan menengah bahwa, yang secara khusus merupakan jenjang yang relatif mempersiapkan anak didik untuk menghadapi kehidupan bermasyarakat, tidak saja aspek pendidikan dalam arti penyiapan untuk berkerja, akan tetapi juga kemampuan anak untuk memehami lingkungan sosial dalam kehidupan sehari-hari.

Pada awal tahun 2000 lalu (Kompas 1/5/01) Harian Umum Kompas melaporkan perkelahian antar siswa SMU di Jakarta Barat, yang sering terjadi di beberapa 
kota di Indonesia. Bahkan hasil penelitian yang menghebohkan warga Bandung sekitar tahun 90-an tentang banyaknya siswa yang telah melakukan hubungan seks dengan lawan jenis di luar nikah. Kehidupan remaja, khususnya di sekolah SMU, memang dalam kondisi perubahan keperibadian sehingga siswa dihadapkan dengan masalah-masalah psikososial seperti; konsep pribadi, tanggung jawab pribadi, prestasi hidup, nilai dan budaya remaja dan pekrjaan, yang secara umum akan memberi warna tersendiri pada beragamnnya perkembangan intelektual anak di sekolah (Unruh dan Alexander, 1970; Husen 1979). Kondisi ini tentunya akan mengarah perlunya sistem pendidikan mempertimbangkan aspek-aspek kejiwaan dan dinamika siswa. Untuk itulah pendidikan menengah, yang semua peserta didiknya sedang mengalami masa transisi, harus menerapkan sistem pendidikan yang kondusif bagi perkembangan masa depan lulusannya.

Dengan mempertimbangan beberapa fenomena tentang pribadi usia remaja di pendidikan menengah serta kondisi sosial-masyarakat dewasa ini, baik dalam sekala regional, nasional dan global, maka tantangan pendidikan di masa depan makin memerlukan antisipasi secara maksimal dari pendidikan nasional. Bagi anak remaja yang sedang mengenyam pendidikan menengah di sekolah, yang lebih banyak menekankan aspek kognitif, ketimbang afektif dan psikomotorik, akan membawa implikasi pada semakin terpinggirkan nilai sosial-masyarakat dalam kehidupan sekarang ini. Di sini penulis, melihat perlunya peran serta keluarga, khususnya orang tua, dalam memberikan pendidikan masa depan bagi para siswa usia remaja. Demikian juga masyarakat, melalui lembaga-lembaga kemasyarakatan, harus berperan dalam memberikan kontribusi dalam mengembangkan anak didik.

Di masa depan bahwa pendidikan menengah di Indonesia, yang perlu menjadi perhatian pemerintah dan masyarakat, termasuk dunia industri yaitu; sekolah membangun proses pendidikan yang sesuai dengan kebutuhan dan perkembangan anak didik, menekankan pada pendidikan pada pengembangan kecakapan hidup (life skill) baik yang bersifat vocational atau pun keperibadian sosial, dan melibatkan orang tua dan masyarakat dalam proses pendidikan.

\section{Daftar Rujukan}

\section{UUSPN No.2. Tahun1989}

PP No. 29 Th. 1990 tentang Pendidikan Menengah

Husen, Torsten. 1979. The School in Question. Oxpord University Press.

Unruh, G.G. dan Alexander, W.M. 1970. Innovation In Secondary Education. Winstin Inc. New York.

Illich, I. 1974. Deschooling Society. Harper \& Row Publisher Inc. New York. 
Goalad, J. 1989. American Education; Social and Political Aspect. Longman. New York

Gutek. G.L. 1991. Education in The United State. Toronto. Allyn bacon.

Rohlen, Thomas.D. 1983. Japan High School. University of California. USA.

Hough, J.R. 1984. Educational Policy; an International Survey. New York.St. Martin' Press.

Boediono. 1997. Pendidikan dan Perubahan Sosial. Aditya Media. Jakarta.

Dewey, John. 1964. Democracy and Education. New York. The Macmillan Company.

Ananta. A. 1993. Ciri Demografis Kualitas Penduduk. Jakarta. FEUI.

Suryadi, A. dan Tilaar, H.R. 1994.Analisis Kebijakan Pendidikan. Jakarta. Rosdakarya

Ruwiyanto. W.1997. Manajemen Sisdiknas Dalam Peningkatan Ketahanan Nasional. Jakarta. Balai Pustaka

Buchari. M. 2001. Pendidikan Antisipatoris. Jakarta. Kanisius.

Tilaar, H.R. 1997. Pengembangan SDM Dalam Era Globalisasi. Jakarta. Grasindo.

Tilaar, H.R. 1999. Pendidikan, Kebudayaan dan Masyarakat Madani. Jakarta. Grasindo.

Syarif, I dan Murtadho, Dengan puisi aku(Editor). 2002. Pendidikan Untuk Masyarakat Indonesia Baru; 70 Tahun H.R. Tilaar. Jakarta Grasindo

Kompas. 20/4/01 